(2) Open Access Full Text Article

REVIEW

\title{
Immunotherapy for the treatment of colorectal tumors: focus on approved and in-clinical-trial monoclonal antibodies
}

This article was published in the following Dove Press journal:

Drug Design, Development and Therapy

II January 2017

Number of times this article has been viewed

\author{
Alex Françoso' \\ Patricia Ucelli Simioni ${ }^{1-3}$ \\ 'Department of Biomedical Science, \\ Faculty of Americana, Americana, \\ ${ }^{2}$ Department of Genetics, Evolution \\ and Bioagents, Institute of Biology, \\ University of Campinas, Campinas, \\ ${ }^{3}$ Department of Biochemistry and \\ Microbiology, Institute of Biosciences, \\ Universidade Estadual Paulista, Rio \\ Claro, São Paulo, Brazil
}

\begin{abstract}
Colorectal cancer is considered a disease of the elderly population. Since the number of geriatric patients continues to rise, monoclonal antibody therapy is the most promising therapy in the recent research. Presently, the monoclonal antibodies most frequently used in the treatment of colorectal tumors are bevacizumab, cetuximab, panitumumab, and ramucirumab. Bevacizumab is a monoclonal antibody that acts on VEGF. Cetuximab and panitumumab act on EGFR. Ramucirumab binds directly to the ligand-binding pocket of VEGFR-2 to block the binding of VEGF-A, VEGF-C, and VEGF-D. These monoclonal antibodies, alone or in association with radiotherapy or chemotherapy, are presenting good results and are increasing patient survival, despite the side effects. Due to the limited number of molecules available, several studies are trying to develop new monoclonal antibodies for the treatment of colorectal tumors. Among those being studied, some recent molecules are in phase I and/or II trials and are yielding advantageous results, such as anti-DR5, anti-Fn14, anti-IGF-1R, anti-EGFR, anti-NRP1, and anti-A33 antibodies. This has been successful in reducing side effects and in treating nonresponsive patients.
\end{abstract}

Keywords: monoclonal antibodies, colorectal tumor, bevacizumab, cetuximab, panitumumab, ramucirumab

\section{Colorectal tumor}

Colorectal cancer is considered a heterogeneous disease, both in relation to the pathogenesis and the clinical signals. ${ }^{1}$ The incidence of colorectal cancer is higher in people between 60 and 70 years of age. Twenty percent of cases occur before the age of 50. Colorectal cancer is more prevalent in the US, Canada, Australia, New Zealand, Denmark, Sweden, and other developed countries. The incidence is 30 times lower in India, South America, and Africa. In Japan, the incidence is increasing gradually, reaching similar rates in the UK, presumably as a result of changes in lifestyle and diet. ${ }^{2-7}$

The discovery of sequences of genes associated with adenoma-carcinoma has contributed to understanding the genetic and epigenetic alterations that drive the formation of colorectal cancer. Among the genetic alterations associated with colorectal cancer, abnormal activation of the Wnt/ $\beta$-catenin signaling pathway has an important role, because $W n t$ pathway is crucial in cell proliferation and migration. ${ }^{8}$

Somatic mutations may play an important role as prognostic or predictive markers for the development of specific therapies in colorectal cancer. These mutations involve genes such as KRAS, BRAF, PIK3CA, AKT1, PTEN, NRAS, and TGFBR2..$^{9-15}$ Therefore, epigenetic and gene silencing events may increase the progression of
Correspondence: Patricia Ucelli Simioni Faculdade de Americana, FAM, Rua Joaquim Boer, 733, Jardim Luciene, 13477-360, Americana, São Paulo, Brazil Tel +551999699 1899 Email psimioni@gmail.com 
colorectal cancer. ${ }^{16}$ This finding opens new possibilities for high-precision laboratory tests such as the identification of molecular markers in screening tests for noninvasive colorectal adenocarcinoma. ${ }^{17}$

\section{Supporting treatment with monoclonal antibodies Approved monoclonal antibodies for therapy}

Several monoclonal antibodies for different therapeutic targets have already been approved for use in patients with tumors. For example, cetuximab and panitumumab are monoclonal antibodies directed at the EGFR. ${ }^{4,18,19}$ Bevacizumab is targeted to the VEGF. ${ }^{20,21}$ Ramucirumab inhibits VEGF and VEGF receptor. ${ }^{22,23}$ Moreover, for the CD20 target, rituximab, ofatumumab, tositumomab, and ibritumomab tiuxetan ${ }^{24-26}$ are used. The antibodies trastuzumab, pertuzumab, trastuzumab, and emtansine are directed HER2/neu. ${ }^{27-33}$ The monoclonal antibody that targets the CD33 molecule is gemtuzumab ozogamicin. ${ }^{31,34}$ Alemtuzumab binds to CD52, ${ }^{35,36}$ while brentuximab vedotin is directed at the CD30 molecule. ${ }^{37}$ Ipilimumab binds to the CTLA4 molecule, among others. ${ }^{38,39}$ Still under development are monoclonal antibodies directed at new or older potential targets, but are not yet approved for use in patients. ${ }^{18,25,40-43}$

\section{Approved monoclonal antibodies for colorectal tumors}

At present, among biological molecules, a few antibodies have their use approved for the treatment of colorectal tumors (Table 1). The four approved monoclonal antibodies showing favorable results for use in the treatment of colorectal cancer are bevacizumab, cetuximab, panitumumab, and ramucirumab, which are detailed in the following section. ${ }^{42,44-46}$

\section{Cetuximab}

Cetuximab is a monoclonal antibody, IgG1 kappa human/ murine chimeric, with constant regions and murine variable regions. It recognizes the extracellular domain of the EGFR and therefore can block the tumor growth. ${ }^{47}$

After binding to the extracellular domain of EGFR, this antibody prevents the signaling and ligand-induced dimerization of the receptor. In this way, it blocks the signals of cell growth and tumor survival. Cetuximab may have the function of mediating antibody-dependent cellular cytotoxicity (ADCC). This monoclonal antibody only achieves dynamic equilibrium after the third week of infusion. ${ }^{4-56}$ In addition, this biological molecule was approved by the US Food and Drug Administration (FDA) for patients with metastatic colorectal cancer ( $\mathrm{mCRC}$ ), especially for patients who do not tolerate irinotecan (a chemotherapeutic drug), and was also associated with irinotecan for patients who do not tolerate oxaliplatin, irinotecan, and 5-fluorouracil (5-FU). ${ }^{57,58}$

Some patients present an anaphylactic reaction. A study has shown that there is a higher incidence of anaphylaxis in people who have a history of allergies to red meat and tick bites. ${ }^{59}$ Cutaneous reactions are considered severe with cetuximab. Cytokine release syndrome occurs usually 1 hour after the infusion. This reaction is usually more severe after the first infusion. ${ }^{60}$ Electrolyte disturbances and neutropenia events may be related to the associated chemotherapy using platinum-based compounds. Eye infections such as ulcerative dermatitis can also occur. ${ }^{61}$

Cetuximab has demonstrated benefits only in a small subset of metastatic patients (KRAS wild-type patients and patients with limited metastatic disease). Alternative strategies that demonstrate promising results for the treatment of rectal cancer during stage II/III include short-course radiotherapy with adjuvant chemotherapy and neoadjuvant FOLFOX (folinic acid, 5-FU, and oxaliplatin)bevacizumab without radiotherapy. ${ }^{62}$

\section{Panitumumab}

Panitumumab is a humanized IgG2 kappa antibody with complementary determining regions (CDRs) of murine origin. It is directed against the EGFR. When compared with cetuximab,

Table I Approved antibodies for the treatment of colorectal tumor

\begin{tabular}{llll}
\hline Monoclonal antibody & Therapeutic target & Mechanism of action & Indication approved (FDA) \\
\hline $\begin{array}{l}\text { Bevacizumab } \\
\text { (humanized } \operatorname{lgGI} \text { ) }\end{array}$ & VEGF & Inhibition of VEGF & Colorectal cancer - palliative treatment \\
$\begin{array}{l}\text { Cetuximab (humanized/ } \\
\text { murine chimeric lgGI) }\end{array}$ & EGFR (ErbBI) & Inhibition of EGFR; ADCC & Colorectal cancer - palliative treatment \\
$\begin{array}{l}\text { Panitumumab } \\
\text { Ramucirumab }\end{array}$ & EGFR & Inhibition of EGFR & Metastatic colorectal carcinoma - with \\
& VEGF receptor-2 & $\begin{array}{l}\text { Blockage of VEGF-A, VEGF-C, } \\
\text { and binding of VEGF-D }\end{array}$ & $\begin{array}{l}\text { EGFR expression } \\
\text { mCRC - in combination with FOLFIRI } \\
\text { (irinotecan, folinic acid, and 5-fluorouracil) }\end{array}$ \\
\hline
\end{tabular}

Abbreviations: ADCC, antibody-dependent cellular cytotoxicity; FDA, US Food and Drug Administration; mCRC, metastatic colorectal cancer. 
it is a murine antibody with reduced portions. However, panitumumab is not able to mediate ADCC. ${ }^{56,63}$ The mechanism of action of panitumumab is due to its binding to EGFR and blocking of this receptor. It inhibits the autophosphorylation of the receptor induced by the ligands of EGFR that internalizes their functions. In conclusion, the monoclonal ligation inhibits cell growth, induces cell apoptosis, and inhibits the production of interleukin-8 and VEGF. ${ }^{64}$

This monoclonal antibody is approved for use in adult patients. Patients with mCRC expressing EGFR in treatment with panitumumab have presented a better response. ${ }^{65}$ The most frequently reported adverse reactions, in monotherapy or in conjunction with chemotherapy, were skin reactions, gastrointestinal disorders, nutrition and metabolic disorders, anorexia, chills, fever, and dyspnea. ${ }^{66}$

\section{Bevacizumab}

Bevacizumab is a recombinant humanized monoclonal IgG1 antibody that binds to VEGF. ${ }^{21,67,68}$ Bevacizumab has an important role in the treatment of colon tumors, but has been used in the treatment of other tumors with favorable results since its role in blocking angiogenesis is of fundamental importance in tumor biology. ${ }^{69}$

Bevacizumab, when used in association with chemotherapy, effectively reduces the progression of tumors in the lungs, colorectal tumors, and breast cancer. The proposed mechanism of action of bevacizumab is related to preventing the interaction of VEGF with VEGFR-1 (Flt-1) and VEGFR-2 (KDR/Flk-1). These receptors are proteins located in the cytoplasmic domain and are connected to the extracellular matrix. VEGF is on top of the cytoplasmic membrane. Bevacizumab binds to VEGF and prevents the proliferation of endothelial cells and formation of blood vessels, as well as decreases the blood supply and reduces tumor interstitial pressure. Thus, the ability of chemotherapy to reach the tumor is increased by the combinatorial treatment. ${ }^{20,70-73}$

In general, in patients with metastatic carcinoma of the colon or rectum, this antibody is used in combination with a fluoropyrimidine chemotherapeutic drug. ${ }^{74,75}$ Bevacizumab is a monoclonal antibody with remarkable antiangiogenic capacity, but is associated with serious cases of gastrointestinal perforation and fistulas, bleeding, bleeding associated with the tumor, and hypertension. Injured or postsurgery patients should not make use of bevacizumab, since it can reduce healing, causing a wound dehiscence and even perforation or abscesses. ${ }^{76}$

\section{Ramucirumab}

In 2015, ramucirumab was approved by the FDA for the treatment of patients with colorectal cancer. ${ }^{77}$ It is a fully humanized
IgG1 monoclonal antibody that targets the extracellular domain of VEGF and VEGFR-2. The binding of the monoclonal antibody inhibits the activation and signaling of these molecules/ receptors. ${ }^{78}$ It is also believed that VEGF and VEGFR-2 mediated angiogenesis in colorectal cancer. ${ }^{22}$ Ramucirumab, in combination with FOLFIRI (irinotecan, folinic acid, and 5-FU), is indicated for the treatment of patients with mCRC with the disease in progression or after therapy with bevacizumab, oxaliplatin, and fluoropyrimidine. The usual dose is $8 \mathrm{mg} / \mathrm{kg}$ ramucirumab plus FOLFIRI every 2 weeks. ${ }^{79}$ Ramucirumab presents the risk of hemorrhage and gastrointestinal hemorrhage, including severe and sometimes fatal hemorrhagic events. ${ }^{23,77-81}$

\section{Monoclonal antibodies in clinical trials from 2012 to 2016}

Bevacizumab is considered a milestone in the treatment of colorectal cancer and is helpful when used in combination with chemotherapy. On the other hand, the anti-EGFR antibodies, also relevant in practice, have limited application for cases of mutations of $K$-ras gene. Since the currently approved monoclonal antibodies act due to the inhibition of VEGF or EGFR, they did not present clinical efficacy in all patients with colorectal tumors. Due to this, the new antibodies under development are a therapeutic promise. These monoclonal antibodies present a different mechanism of action and the possibility of reduced side effects. However, detailed clinical trials are under way to verify if these new molecules are more effective than the already approved antibodies. Also, these trials are necessary to determine their drawbacks and adverse effects. The newest developments in monoclonal antibodies for immunotherapy are detailed in Table 2 and in the following section.

\section{Fibroblast growth factor-inducible I4 (FnI4) molecules}

RG7212 is a monoclonal antibody in phase I immunotherapy study. It is a first-in-class, fully humanized $\operatorname{IgG1}$ kappa monoclonal antibody. RG7212 blocks TNF (tumour necrosis factor)-like weak inducer of apoptosis (TWEAK) by binding to the Fn14 receptor. TWEAK and Fn14 are a ligand-receptor pair frequently overexpressed in solid tumors. TWEAK induces cell proliferation, survival, and NF- $\mathrm{KB}$ signaling. RG7212 had good tolerability and favorable pharmacokinetics in combination therapies in patients with Fn14-positive tumors. ${ }^{82}$

\section{Anti-DR5 antibodies}

Tigatuzumab is a humanized monoclonal IgG1 agonist of human DR5, also known as member 10b of the TNF receptor 
Table 2 New monoclonal antibodies under clinical trials for the treatment of colorectal tumor

\begin{tabular}{|c|c|c|c|}
\hline Monoclonal antibody & $\begin{array}{l}\text { Therapeutic } \\
\text { target }\end{array}$ & Mechanism of action & Trials \\
\hline $\begin{array}{l}\text { RG72 I2 (fully humanized } \\
\text { lgGI kappa) }\end{array}$ & FnI4 & $\begin{array}{l}\text { Inhibits TWEAK; reduces proliferation, survival, } \\
\text { and NF- } \mathrm{KB} \text { signaling }\end{array}$ & Phase I trial for solid tumors \\
\hline $\begin{array}{l}\text { Tigatuzumab (CS-1008; } \\
\text { humanized } \lg \mathrm{I} I)\end{array}$ & $\begin{array}{l}\text { DR5 (TNFRSFIOB } \\
\text { or TRAIL-R2) }\end{array}$ & $\begin{array}{l}\text { Agonist of DR5, apoptosis induction, and } \\
\text { cytotoxic activity }\end{array}$ & Phase II trial for mCRC \\
\hline Nimotuzumab (humanized IgGI) & $\begin{array}{l}\text { Extracellular } \\
\text { domain of EGFR }\end{array}$ & Inhibits EGFR & $\begin{array}{l}\text { Phase II trial for local advanced } \\
\text { colorectal tumor }\end{array}$ \\
\hline $\begin{array}{l}\text { Figitumumab (fully humanized } \\
\lg G 2 \text { ) }\end{array}$ & IGF-IR & Reduces the activation of IGF-IR & $\begin{array}{l}\text { Phase II clinical trial for refractory } \\
\mathrm{mCRC}\end{array}$ \\
\hline $\begin{array}{l}\text { Robatumumab (R-I507, I9DI2, } \\
\text { or SCH 7I7454; fully humanized } \\
\text { IgGI kappa isotype) }\end{array}$ & IGF-IR & $\begin{array}{l}\text { Antagonist of IGF-IR, inhibits VEGF and } \\
\text { angiogenesis }\end{array}$ & $\begin{array}{l}\text { Phase II study for advanced } \\
\text { colorectal cancer }\end{array}$ \\
\hline KRN330 (fully humanized Ig) & A33 glycoprotein & $\begin{array}{l}\text { Stimulates CTL response against A33-positive } \\
\text { colorectal cancer }\end{array}$ & $\begin{array}{l}\text { Phase I/II study, in combination with } \\
\text { irinotecan for } \mathrm{mCRC}\end{array}$ \\
\hline I-huA33 (fully humanized IgGI) & A33 glycoprotein & $\begin{array}{l}\text { Stimulates CTL response against A33-positive } \\
\text { colorectal cancer }\end{array}$ & $\begin{array}{l}\text { Phase I trial, in combination with } \\
\text { capecitabine for } \mathrm{mCRC}\end{array}$ \\
\hline $\begin{array}{l}\text { MNRPI685A (fully humanized } \\
\operatorname{lgGI} \text { isotype) }\end{array}$ & NRPI & $\begin{array}{l}\text { Targets the VEGF binding domain of NRPI; } \\
\text { reduces angiogenesis, cell survival, migration, } \\
\text { and invasion }\end{array}$ & $\begin{array}{l}\text { Phase I trial, in combination with } \\
\text { anti-VEGF therapies to advanced } \\
\text { tumors }\end{array}$ \\
\hline $\begin{array}{l}\text { Dalotuzumab (MK-0646; fully } \\
\text { humanized } \lg G \mathrm{I} \text { isotype) }\end{array}$ & IGF-IR & $\begin{array}{l}\text { Antagonist of IGF-IR; inhibits IGF-I - and } \\
\text { IGF-2-mediated tumor cell proliferation, IGF-IR } \\
\text { autophosphorylation and Akt phosphorylation }\end{array}$ & $\begin{array}{l}\text { Phase I study, in combination with } \\
\text { cetuximab and irinotecan } \\
\text { for advanced colorectal cancer }\end{array}$ \\
\hline $\begin{array}{l}\text { Drozitumab (anti-TRAIL, } \\
\text { PRO-95780, RG7425; fully } \\
\text { humanized lgGI) }\end{array}$ & DR5 & $\begin{array}{l}\text { Agonist of DR5, apoptosis induction, cytotoxic } \\
\text { activity }\end{array}$ & $\begin{array}{l}\text { Phase I study, in combination } \\
\text { with first-line mFOLFOX } 6 \text { plus } \\
\text { bevacizumab for mCRC }\end{array}$ \\
\hline
\end{tabular}

Abbreviations: 5-FU, 5-fluorouracil; CTL, cytotoxic T-lymphocyte; Fnl4, fibroblast growth factor-inducible I4; mCRC, metastatic colorectal cancer; mFOLOFOX, oxaliplatin, folinic acid, 5-FU in combination with either panitumumab or cetuximab; TWEAK, tumour necrosis factor-like weak inducer of apoptosis.

superfamily (TNFRSF10B) or TRAIL-R2. DR5 is a protein overexpressed in many kinds of tumors. It is under clinical trial in patients with mCRC. ${ }^{83}$

Drozitumab is a fully humanized IgG1 that also binds with DR5. It is under phase I study combined with FOLFOX6 and bevacizumab. Patients with $\mathrm{mCRC}$ presented a partial response in this trial. ${ }^{84}$

\section{Anti-EGFR antibodies}

Nimotuzumab is a humanized monoclonal IgG1 antibody that binds to the EGFR with intermediate affinity. ${ }^{85,86}$ It has presented good efficacy in phase II trials of radiotherapy and in combination with capecitabine in advanced rectal cancer. ${ }^{87}$

\section{Anti-IGF-IR antibodies}

Robatumumab is an IGF-1R monoclonal antibody under phase II study in patients with advanced colorectal cancer. ${ }^{88}$ It acts by inhibiting tumor-derived VEGF and, indirectly, angiogenesis. ${ }^{89}$ However, few patients appeared to benefit from treatment with robatumumab. ${ }^{88}$

Dalotuzumab (MK-0646) is a recombinant humanized IgG1 mAb, also against the IGF-1R. It is under a phase I study in combination with cetuximab and irinotecan and is given to patients with advanced colorectal cancer. ${ }^{90}$ Robatumumab acts by reducing IGF-1- and IGF-2-mediated tumor cell proliferation, IGF-1R autophosphorylation, and Akt phosphorylation.

Also, figitumumab is a monoclonal antibody under a phase II clinical trial for patients with refractory $\mathrm{mCRC}$. It is a humanized IgG2 isotype that binds and reduces the activation of IGF-1R. However, no partial or complete responses occurred in this trial, and further study of figitumumab was not supported. ${ }^{91}$

\section{Anti-A33 antibodies}

KRN330 is a fully humanized monoclonal antibody directed against A33. A33 is a $43 \mathrm{kDa}$ transmembrane glycoprotein of the immunoglobulin superfamily that is highly expressed in intestinal epithelium and expressed in $95 \%$ of colorectal cancers. This monoclonal antibody seems to stimulate cytotoxic T-lymphocyte (CTL) response against A33-positive colorectal cancers. In the phase II study, the prespecified objective response rate to the treatment with KRN330 and irinotecan was not met. ${ }^{92}$

I-huA33, another anti-33 monoclonal antibody, combined with capecitabine, is under a phase I trial for mCRC. In this trial, I-huA33 is achieving specific targeting to colorectal cancer metastases and is safely combined with chemotherapy. ${ }^{93}$ 


\section{Anti-NRPI antibodies}

MNRP1685A is a fully humanized IgG1 directed against NRP1. NRP1 is overexpressed by certain tumor cells. This monoclonal antibody has potential antineoplastic activities by preventing coupling of NRP1 to VEGFR-2 and potentially inhibiting VEGF-mediated signaling and angiogenesis. MNRP1685A, in combination with antiVEGF therapies, may present an enhanced antiangiogenic effect and is under phase I trials in patients with advanced solid tumors. ${ }^{94}$

\section{Future perspectives}

Presently, new strategic trials are being developed due to the elevated cost of new agents and reduced number of molecules available. Furthermore, molecular-targeted agents such as antiangiogenic agents (bevacizumab, aflibercept, and regorafenib) and anti-EGFR agents (cetuximab and panitumumab) have been associated with chemotherapeutic drugs (fluoropyrimidine, oxaliplatin, and irinotecan), as described in the following section.

The combination of monoclonal antibodies anti-VEGF or anti-EGFR with chemotherapy has shown good clinical activity in cases of metastatic colorectal tumors. However, the use of both molecules combined with chemotherapy presented several adverse outcomes. Clinical trials are under development to test the effects of bevacizumab plus erlotinib, as well as bevacizumab plus tegafur/uracil and leucovorin, as a first-line treatment for patients with mCRC. ${ }^{95}$ Also, STRATEGIC-1, a phase III trial, is in progress with the purpose of creating global information on the treatment sequence for patients with unresectable RAS wild-type colorectal cancer. In this trial, FOLFIRI + cetuximab + oxaliplatin + bevacizumab is compared to OPTIMOX + bevacizumab + irinotecan..$^{96}$

Panitumumab or bevacizumab with FOLFIRI (SPIRITT) is also under evaluation as a second-line treatment. This combination presented similar efficacy as oxaliplatinbased chemotherapy with bevacizumab, with expected toxicities. ${ }^{97}$

Necitumumab plus modified FOLFOX6 (oxaliplatin, folinic acid, 5-FU in combination with either panitumumab or cetuximab) was recommended as the first-line treatment for patients with $R A S$ mutation and as first-line treatment for locally advanced cancers or mCRC and is also in evaluation..$^{98}$

Conversely, dalotuzumab plus irinotecan and cetuximab did not improve survival outcome in KRAS wild-type mCRC.${ }^{99}$ Meta-analysis studies showed that anti-EGFR monoclonal antibodies alone or in combination with others (FOLFIRI \pm cetuximab; FOLFOX $4 \pm$ cetuximab; oxaliplatin or irinotecan-based chemotherapy, bevacizumab \pm panitumumab; bevacizumab, capecitabine, oxaliplatin \pm cetuximab, and irinotecan \pm cetuximab) did not present efficacy in patients with mCRC containing KRAS mutations. ${ }^{100-102}$

\section{Conclusion}

This review concludes that the repertoire of approved monoclonal antibodies used to treat patients with colorectal tumors, especially in cases of malignant and metastatic tumors, is very limited. Nowadays, these biological molecules belong to only two classes of monoclonal antibodies: specific binders of VEGF or of EGFR. Despite the occurrence of side effects and higher costs of the treatment, researchers are constantly looking for new monoclonal antibodies for the treatment of colorectal tumors. New classes of molecules are under clinical trials with promising results.

A further possibility for identifying tumors is the use of biomarkers to optimize therapeutic efficacy and reduce toxicity. One of the current trends is the individualization of systemic treatment, which has become possible due to molecular biology tools and statistical analysis based on biologically plausible principles.

\section{Acknowledgment}

This work was supported by São Paulo Research Foundation (FAPESP), grant numbers 2013/20258-2 and 2016/19321-0.

\section{Disclosure}

The authors report no conflicts of interest in this work.

\section{References}

1. IJspeert JEG, Vermeulen L, Meijer GA, Dekker E. Serrated neoplasiarole in colorectal carcinogenesis and clinical implications. Nat Rev Gastroenterol Hepatol. 2015;12(7):401-409.

2. Rossi L, Veltri E, Zullo A, et al. Metastatic colorectal cancer first-line treatment with bevacizumab: the impact of K-ras mutation. Onco Targets Ther. 2013;6:1761-1769.

3. Li X, Shan B-E, Wang J, et al. Incidence and risk of treatment-related mortality with anti-epidermal growth factor receptor monoclonal antibody in cancer patients: a meta-analysis of 21 randomized controlled trials. PLoS One. 2013;8(11):e81897.

4. Price TJ, Peeters M, Kim TW, et al. Panitumumab versus cetuximab in patients with chemotherapy-refractory wild-type KRAS exon 2 metastatic colorectal cancer (ASPECCT): a randomised, multicentre, open-label, non-inferiority phase 3 study. Lancet Oncol. 2014;15(6): 569-579.

5. Nakagawa H, Ito $\mathrm{H}$, Hosono $\mathrm{S}$, et al. Changes in trends in colorectal cancer incidence rate by anatomic site between 1978 and 2004 in Japan. Eur J Cancer Prev. Epub 2016 May 4.

6. Hibler E. Epigenetics and colorectal neoplasia: the evidence for physical activity and sedentary behavior. Curr Colorectal Cancer Rep. 2015; 11(6):388-396.

7. Huxley RR, Ansary-Moghaddam A, Clifton P, Czernichow S, Parr CL, Woodward M. The impact of dietary and lifestyle risk factors on risk of colorectal cancer: a quantitative overview of the epidemiological evidence. Int J Cancer. 2009;125(1):171-180. 
8. Sparks AB, Morin PJ, Vogelstein B, Kinzler KW. Mutational analysis of the APC/beta-catenin/Tcf pathway in colorectal cancer. Cancer Res. 1998; 58(6):1130-1134.

9. Baba Y, Nosho K, Shima K, et al. Phosphorylated AKT expression is associated with PIK3CA mutation, low stage, and favorable outcome in 717 colorectal cancers. Cancer. 2011;117(7):1399-1408.

10. De Roock W, Claes B, Bernasconi D, et al. Effects of KRAS, BRAF, NRAS, and PIK3CA mutations on the efficacy of cetuximab plus chemotherapy in chemotherapy-refractory metastatic colorectal cancer: a retrospective consortium analysis. Lancet Oncol. 2010;11:753-762.

11. Dienstmann R, Vilar E, Tabernero J. Molecular predictors of response to chemotherapy in colorectal cancer. Cancer J. 2011;17(2): 114-126.

12. Fernández-Peralta AM, Nejda N, Oliart S, et al. Significance of mutations in TGFBR2 and BAX in neoplastic progression and patient outcome in sporadic colorectal tumors with high-frequency microsatellite instability. Cancer Genet Cytogenet. 2005;157(1):18-24.

13. Haigis KM, Kendall KR, Wang Y, et al. Differential effects of oncogenic $\mathrm{K}$-Ras and N-Ras on proliferation, differentiation and tumor progression in the colon. Nat Genet. 2008;40(5):600-608.

14. Negri FV, Bozzetti C, Lagrasta CA, et al. PTEN status in advanced colorectal cancer treated with cetuximab. Br J Cancer. 2010;102(1): $162-164$.

15. Sartore-Bianchi A, Martini M, Molinari F, et al. PIK3CA mutations in colorectal cancer are associated with clinical resistance to EGFRtargeted monoclonal antibodies. Cancer Res. 2009;69(5):1851-1857.

16. Arvelo F, Sojo F, Cotte C. Biology of colorectal cancer. Ecancermedicalscience. 2015;9:520.

17. Dickinson BT, Kisiel J, Ahlquist DA, Grady WM. Molecular markers for colorectal cancer screening. Gut. 2015;64(9):1485-1494.

18. Sorich MJ, Wiese MD, Rowland A, Kichenadasse G, McKinnon RA, Karapetis CS. Extended RAS mutations and anti-EGFR monoclonal antibody survival benefit in metastatic colorectal cancer: a meta-analysis of randomized, controlled trials. Ann Oncol. 2015;26(1):13-21.

19. Huang L, Liu Z, Deng D, et al. Anti-epidermal growth factor receptor monoclonal antibody-based therapy for metastatic colorectal cancer: a meta-analysis of the effect of PIK3CA mutations in KRAS wild-type patients. Arch Med Sci. 2014;10(1):1-9.

20. Ranieri G, Patruno R, Ruggieri E, Montemurro S, Valerio P, Ribatti D Vascular endothelial growth factor (VEGF) as a target of bevacizumab in cancer: from the biology to the clinic. Curr Med Chem. 2006;13(16): 1845-1857.

21. Culy C. Bevacizumab: antiangiogenic cancer therapy. Drugs Today (Barc). 2005;41(1):23-36.

22. Garcia-Carbonero R, Rivera F, Maurel J, et al. An open-label phase II study evaluating the safety and efficacy of ramucirumab combined with mFOLFOX-6 as first-line therapy for metastatic colorectal cancer. Oncologist. 2014;19(4):350-351.

23. Bach PB. Ramucirumab for colon cancer and the problem of rising prices independent of benefits. Oncologist. 2015;20(9):983-984.

24. Jeong W-J, Cha P-H, Choi K-Y. Strategies to overcome resistance to epidermal growth factor receptor monoclonal antibody therapy in metastatic colorectal cancer. World J Gastroenterol. 2014;20(29): 9862-9871.

25. Rosati G, Aprile G, Cardellino GG, Avallone A. A review and assessment of currently available data of the EGFR antibodies in elderly patients with metastatic colorectal cancer. J Geriatr Oncol. 2016;7(2): 134-141.

26. Reichert JM, Dhimolea E. The future of antibodies as cancer drugs. Drug Discov Today. 2012;17(17-18):954-963.

27. Shak S; Herceptin Multinational Investigator Study Group. Overview of the trastuzumab (Herceptin) anti-HER2 monoclonal antibody clinical program in HER2-overexpressing metastatic breast cancer. Semin Oncol. 1999;26(4 suppl 12):71-77.

28. Doebele RC, Oton AB, Peled N, Camidge DR, Bunn PA. New strategies to overcome limitations of reversible EGFR tyrosine kinase inhibitor therapy in non-small cell lung cancer. Lung Cancer. 2010;69(1): $1-12$.
29. Fornier M, Munster P, Seidman AD. Update on the management of advanced breast cancer. Oncology (Williston Park). 1999;13(5):663-664.

30. Dillman RO. Perceptions of herceptin: a monoclonal antibody for the treatment of breast cancer. Cancer Biother Radiopharm. 1999;14(1):5-10.

31. Bates SE, Amiri-Kordestani L, Giaccone G. Drug development: portals of discovery. Clin Cancer Res. 2012;18(1):23-32.

32. Brenner TL, Adams VR. First MAb approved for treatment of metastatic breast cancer. J Am Pharm Assoc (Wash). 1999;39(2):236-238.

33. Swain SM, Kim S-B, Cortés J, et al. Pertuzumab, trastuzumab, and docetaxel for HER2-positive metastatic breast cancer (CLEOPATRA study): overall survival results from a randomised, double-blind, placebo-controlled, phase 3 study. Lancet Oncol. 2013;14(6):461-471.

34. Hamann PR, Hinman LM, Hollander I, et al. Gemtuzumab ozogamicin, a potent and selective anti-CD33 antibody - calicheamicin conjugate for treatment of acute myeloid leukemia. Bioconjug Chem. 2002;13(1): 47-58.

35. Bakr MA, Nagib AM, Donia AF. Induction immunosuppressive therapy in kidney transplantation. Exp Clin Transplant. 2014;12(suppl 1):60-69.

36. Rodrigues EB, Farah ME, Maia M, et al. Therapeutic monoclonal antibodies in ophthalmology. Prog Retin Eye Res. 2009;28(2):117-144.

37. Amarapurkar P, Rosenblatt JD, Pereira D. Brentuximab: a major advance in treatment of CD30-positive malignancies. Int $J$ Hematol Oncol. 2015;4(6):219-232.

38. Reck M, Heigener D, Reinmuth N. Immunotherapy for small-cell lung cancer: emerging evidence. Future Oncol. 2016;12(7):931-943.

39. Berman D, Parker SM, Siegel J, et al. Blockade of cytotoxic T-lymphocyte antigen-4 by ipilimumab results in dysregulation of gastrointestinal immunity in patients with advanced melanoma. Cancer Immun. 2010;10:11

40. Topalian SL, Hodi FS, Brahmer JR, et al. Safety, activity, and immune correlates of anti-PD-1 antibody in cancer. NEngl J Med. 2012;366(26): 2443-2454.

41. Bittner N, Ostoros G, Géczi L. New treatment options for lung adenocarcinoma - in view of molecular background. Pathol Oncol Res. 2014;20(1):11-25.

42. Zhu Z, Yan L. Next generation of antibody therapy for cancer. Chin J Cancer. 2011;30(5):293-302.

43. Davies M. New modalities of cancer treatment for NSCLC: focus on immunotherapy. Cancer Manag Res. 2014;6:63-75.

44. Guan M, Zhou Y-P, Sun J-L, Chen S-C. Adverse events of monoclonal antibodies used for cancer therapy. Biomed Res Int. 2015;2015: 428169.

45. Baldo BA. Adverse events to monoclonal antibodies used for cancer therapy: focus on hypersensitivity responses. Oncoimmunology. 2013;2: e26333.

46. Glassman PM, Balthasar JP. Mechanistic considerations for the use of monoclonal antibodies for cancer therapy. Cancer Biol Med. 2014; 11(1):20-33.

47. Primrose JN, Falk S, Finch-Jones M, et al. A randomized clinical trial of chemotherapy compared to chemotherapy in combination with cetuximab in k-RAS wild-type patients with operable metastases from colorectal cancer: the new EPOC study. ASCO Meet Abstr. 2013;31:3504.

48. Bourhis J, Rivera F, Mesia R, et al. Phase I/II study of cetuximab in combination with cisplatin or carboplatin and fluorouracil in patients with recurrent or metastatic squamous cell carcinoma of the head and neck. J Clin Oncol. 2006;24(18):2866-2872.

49. Mesía R, Palmero R, Cos M, Vilajosana E, Vázquez S. Rapid palliation of symptoms with platinum-based chemotherapy plus cetuximab in recurrent oral cancer: a case report. Head Neck Oncol. 2010;2:3.

50. Licitra L, Mesia R, Rivera F, et al. Evaluation of EGFR gene copy number as a predictive biomarker for the efficacy of cetuximab in combination with chemotherapy in the first-line treatment of recurrent and/or metastatic squamous cell carcinoma of the head and neck: EXTREME study. Ann Oncol. 2011;22(5):1078-1087.

51. Pueyo G, Mesia R, Figueras A, et al. Cetuximab may inhibit tumor growth and angiogenesis induced by ionizing radiation: a preclinical rationale for maintenance treatment after radiotherapy. Oncologist. 2010; 15(9):976-986. 
52. Taberna M, Rullan AJ, Hierro C, et al. Late toxicity after radical treatment for locally advanced head and neck cancer. Oral Oncol. 2015;51(8): 795-799.

53. Mesía R, Pastor M, Grau JJ, del Barco E. SEOM, SEOM clinical guidelines for the treatment of head and neck cancer (HNC) 2013. Clin Transl Oncol. 2013;15(12):1018-1024.

54. Bernier J, Bonner J, Vermorken JB, et al. Consensus guidelines for the management of radiation dermatitis and coexisting acne-like rash in patients receiving radiotherapy plus EGFR inhibitors for the treatment of squamous cell carcinoma of the head and neck. Ann Oncol. 2008; 19(1):142-149.

55. Mesía R, Rueda A, Vera R, et al. Adjuvant therapy with cetuximab for locally advanced squamous cell carcinoma of the oropharynx: results from a randomized, phase II prospective trial. Ann Oncol. 2013;24(2): 448-453.

56. Monteverde M, Milano G, Strola G, et al. The relevance of ADCC for EGFR targeting: a review of the literature and a clinically-applicable method of assessment in patients. Crit Rev Oncol Hematol. 2015; 95(2):179-190.

57. Stintzing S, Fischer von Weikersthal L, Decker U, et al. FOLFIRI plus cetuximab versus FOLFIRI plus bevacizumab as first-line treatment for patients with metastatic colorectal cancer-subgroup analysis of patients with KRAS: mutated tumours in the randomised German AIO study KRK-0306. Ann Oncol. 2012;23(7):1693-1699.

58. Heinemann V, von Weikersthal LF, Decker T, et al. FOLFIRI plus cetuximab versus FOLFIRI plus bevacizumab as first-line treatment for patients with metastatic colorectal cancer (FIRE-3): a randomised, open-label, phase 3 trial. Lancet Oncol. 2014;15(10):1065-1075.

59. Dupont B, Mariotte D, Clarisse B, et al. Risk factors associated with hypersensitivity reactions to cetuximab: anti-cetuximab IgE detection as screening test. Future Oncol. 2014;10(14):2133-2140.

60. Yamaguchi K, Watanabe T, Satoh T, et al. Severe infusion reactions to cetuximab occur within $1 \mathrm{~h}$ in patients with metastatic colorectal cancer: results of a nationwide, multicenter, prospective registry study of 2126 patients in Japan. Jpn J Clin Oncol. 2014;44(6):541-546.

61. Wang Q, Qi Y, Zhang D, et al. Electrolyte disorders assessment in solid tumor patients treated with anti-EGFR monoclonal antibodies: a pooled analysis of 25 randomized clinical trials. Tumour Biol. 2015; 36(5):3471-3482.

62. Murphy JE, Ryan DP. American Society of Clinical Oncology 2010 colorectal update. Expert Rev Anticancer Ther. 2010;10(9):1371-1373.

63. Lonberg N. Human antibodies from transgenic animals. Nat Biotechnol. 2005;23(9):1117-1125.

64. Kumar SS, Price TJ, Mohyieldin O, Borg M, Townsend A, Hardingham JE. KRAS G13D mutation and sensitivity to cetuximab or panitumumab in a colorectal cancer cell line model. Gastrointest Cancer Res. 2014;7(1):23-26.

65. Tay RY, Wong R, Hawkes EA. Treatment of metastatic colorectal cancer: focus on panitumumab. Cancer Manag Res. 2015;7:189-198.

66. Takahashi H, Ishikawa T, Iwata N, et al. [A case of postoperative colon cancer with peritoneal dissemination in which a long-term response was achieved using panitumumab maintenance therapy]. Gan To Kagaku Ryoho. 2014;41(12):1701-1703.

67. Krämer I, Lipp H-P. Bevacizumab, a humanized anti-angiogenic monoclonal antibody for the treatment of colorectal cancer. J Clin Pharm Ther. 2007;32(1):1-14.

68. Wu W, Xu L, Liu ZZ, et al. [Acceptable safety of bevacizumab therapy in combination with chemotherapy in patients with advanced lung cancer]. Zhongguo Fei Ai Za Zhi. 2009;12(3):231-235.

69. Farschtschi S, Kollmann P, Dalchow C, Stein A, Mautner V-F. Reduced dosage of bevacizumab in treatment of vestibular schwannomas in patients with neurofibromatosis type 2. Eur Arch Otorhinolaryngol. 2015;272(12):3857-3860.

70. Bonomi PD, Mace J, Mandanas RA, et al. Randomized phase II study of cetuximab and bevacizumab in combination with two regimens of paclitaxel and carboplatin in chemonaive patients with stage IIIB/IV non-small-cell lung cancer. J Thorac Oncol. 2013;8(3): $338-345$.
71. Herbst RS, Johnson DH, Mininberg E, et al. Phase I/II trial evaluating the anti-vascular endothelial growth factor monoclonal antibody bevacizumab in combination with the HER-1/epidermal growth factor receptor tyrosine kinase inhibitor erlotinib for patients with recurrent non-small-cell lung cancer. J Clin Oncol. 2005;23:2544-2555.

72. Lynch TJ, Spigel DR, Brahmer J, et al. Safety and effectiveness of bevacizumab-containing treatment for non-small-cell lung cancer: final results of the ARIES observational cohort study. J Thorac Oncol. 2014; 9(9):1332-1339.

73. Scales SJ, Pepperkok R, Kreis TE. Visualization of ER-to-Golgi transport in living cells reveals a sequential mode of action for COPII and COPI. Cell. 1997;90(6):1137-1148.

74. Ait-Belkacem R, Berenguer C, Villard C, et al. Monitoring therapeutic monoclonal antibodies in brain tumor. MAbs. 2014;6(6): 1385-1393.

75. Liu S, Kurzrock R. Understanding toxicities of targeted agents: implications for anti-tumor activity and management. Semin Oncol. 2015; 42(6):863-875.

76. Ina K, Furuta R, Kataoka T, et al. Adverse effects of bevacizumab during treatment for metastatic colorectal cancer. J Anal Oncol. 2015;4: 24-29.

77. Ursem C, Van Loon K, Venook A. Adjuvant therapy trials. Cancer J. 2016;22(3):196-198.

78. Verdaguer H, Tabernero J, Macarulla T. Ramucirumab in metastatic colorectal cancer: evidence to date and place in therapy. Ther Adv Med Oncol. 2016;8(3):230-242.

79. Yoshino T, Yamazaki K, Gotoh M, et al. Safety and pharmacokinetics of second-line ramucirumab plus FOLFIRI in Japanese patients with metastatic colorectal carcinoma. Anticancer Res. 2015;35(7): 4003-4007.

80. Pohl M, Schmiegel W. Therapeutic strategies in diseases of the digestive tract -2015 and beyond targeted therapies in colon cancer today and tomorrow. Dig Dis. 2016;34(5):574-579.

81. Yan Y, Grothey A. Molecular profiling in the treatment of colorectal cancer: focus on regorafenib. Onco Targets Ther. 2015;8:2949-2957.

82. Lassen UN, Meulendijks D, Siu LL, et al. A phase I monotherapy study of RG7212, a first-in-class monoclonal antibody targeting TWEAK signaling in patients with advanced cancers. Clin Cancer Res. 2015;21(2):258-266.

83. Ciprotti M, Tebbutt NC, Lee F-T, et al. Phase I imaging and pharmacodynamic trial of CS-1008 in patients with metastatic colorectal cancer. J Clin Oncol. 2015;33(24):2609-2616.

84. Rocha Lima CM, Bayraktar S, Flores AM, et al. Phase Ib study of drozitumab combined with first-line mFOLFOX6 plus bevacizumab in patients with metastatic colorectal cancer. Cancer Invest. 2012;30(10): $727-731$.

85. Okamoto I. Nimotuzumab, a novel monoclonal antibody to the epidermal growth factor receptor, in the treatment of non-small cell lung cancer. Lung Cancer Targets Ther. 2011;2:59.

86. Ramakrishnan MS, Eswaraiah A, Crombet T, et al. Nimotuzumab, a promising therapeutic monoclonal for treatment of tumors of epithelial origin. MAbs. 2009;1(1):41-48.

87. Jin T, Zhu Y, Luo J-L, et al. Prospective phase II trial of nimotuzumab in combination with radiotherapy and concurrent capecitabine in locally advanced rectal cancer. Int J Colorectal Dis. 2015;30(3):337-345.

88. Lin EH, Lenz H-J, Saleh MN, et al. A randomized, phase II study of the anti-insulin-like growth factor receptor type 1 (IGF-1R) monoclonal antibody robatumumab (SCH 717454) in patients with advanced colorectal cancer. Cancer Med. 2014;3(4):988-997.

89. Bid HK, Zhan J, Phelps DA, Kurmasheva RT, Houghton PJ. Potent inhibition of angiogenesis by the IGF-1 receptor-targeting antibody SCH717454 is reversed by IGF-2. Mol Cancer Ther. 2012;11(3): 649-659.

90. Doi T, Muro K, Yoshino T, et al. Phase 1 pharmacokinetic study of MK-0646 (dalotuzumab), an anti-insulin-like growth factor-1 receptor monoclonal antibody, in combination with cetuximab and irinotecan in Japanese patients with advanced colorectal cancer. Cancer Chemother Pharmacol. 2013;72(3):643-652. 
91. Becerra CR, Salazar R, Garcia-Carbonero R, et al. Figitumumab in patients with refractory metastatic colorectal cancer previously treated with standard therapies: a nonrandomized, open-label, phase II trial. Cancer Chemother Pharmacol. 2014;73(4):695-702.

92. Bendell JC, Lenz H-J, Ryan T, et al. Phase 1/2 study of KRN330, a fully human anti-A33 monoclonal antibody, plus irinotecan as second-line treatment for patients with metastatic colorectal cancer. Invest $\mathrm{New}$ Drugs. 2014;32(4):682-690.

93. Herbertson RA, Tebbutt NC, Lee F-T, et al. Targeted chemoradiation in metastatic colorectal cancer: a phase I trial of 131I-huA33 with concurrent capecitabine. J Nucl Med. 2014;55(4):534-539.

94. Weekes CD, Beeram M, Tolcher AW, et al. A phase I study of the human monoclonal anti-NRP1 antibody MNRP1685A in patients with advanced solid tumors. Invest New Drugs. 2014;32(4):653-660.

95. Tournigand C, Chibaudel B, Samson B, et al. Bevacizumab with or without erlotinib as maintenance therapy in patients with metastatic colorectal cancer (GERCOR DREAM; OPTIMOX3): a randomised, open-label, phase 3 trial. Lancet Oncol. 2015;16(15):1493-1505.

96. Chibaudel B, Bonnetain F, Tournigand C, et al. STRATEGIC-1: a multiple-lines, randomized, open-label GERCOR phase III study in patients with unresectable wild-type RAS metastatic colorectal cancer. BMC Cancer. 2015;15:496.

97. Hecht JR, Cohn A, Dakhil S, et al. SPIRITT: a randomized, multicenter, phase II study of panitumumab with FOLFIRI and bevacizumab with FOLFIRI as second-line treatment in patients with unresectable wild type KRAS metastatic colorectal cancer. Clin Colorectal Cancer. 2015;14:72-80.
98. Elez E, Hendlisz A, Delaunoit T, et al. Phase II study of necitumumab plus modified FOLFOX6 as first-line treatment in patients with locally advanced or metastatic colorectal cancer. Br J Cancer. 2016;114(4):372-380.

99. Sclafani F, Kim TY, Cunningham D, et al. A randomized phase II/III study of dalotuzumab in combination with cetuximab and irinotecan in chemorefractory, KRAS wild-type, metastatic colorectal cancer. J Natl Cancer Inst. 2015;107(12):djv258.

100. Rowland A, Dias MM, Wiese MD, et al. Meta-analysis of BRAF mutation as a predictive biomarker of benefit from anti-EGFR monoclonal antibody therapy for RAS wild-type metastatic colorectal cancer. $\mathrm{Br}$ J Cancer. 2015;112(12):1888-1894.

101. Meier-Kriesche HU, Schold JD, Kaplan B. Long-term renal allograft survival: have we made significant progress or is it time to rethink our analytic and therapeutic strategies? Am J Transplant. 2004; 4(8):1289-1295.

102. Bokemeyer C, Köhne CH, Ciardiello F, et al. FOLFOX4 plus cetuximab treatment and RAS mutations in colorectal cancer. Eur J Cancer. 2015; 51(10):1243-1252.
Drug Design, Development and Therapy

\section{Publish your work in this journal}

Drug Design, Development and Therapy is an international, peerreviewed open-access journal that spans the spectrum of drug design and development through to clinical applications. Clinical outcomes, patient safety, and programs for the development and effective, safe, and sustained use of medicines are the features of the journal, which

\section{Dovepress}

has also been accepted for indexing on PubMed Central. The manuscript management system is completely online and includes a very quick and fair peer-review system, which is all easy to use. Visit http://www.dovepress.com/testimonials.php to read real quotes from published authors. 